\title{
Assessment of the Rotation of Exterior Bridge Girders Due to Construction Loading Using TAEG Software
}

\author{
Md Ashiquzzaman ${ }^{1}$, Justin Schmeltz ${ }^{2}$, Ahmed Ibrahim ${ }^{3}$ Will Lindquist $^{4}$, and Riyadh Hindi ${ }^{5}$ \\ ${ }^{1}$ Ph.D., Parks College of Engineering, Aviation and Technology, Saint Louis University, St. Louis, MO, 63103, \\ USA \\ ${ }^{2}$ Engineer, Horner and Shifrin, Inc., St. Louis, MO, 63103, USA \\ ${ }^{3}$ Assistant Professor, Department of Civil Engineering, University of Idaho, Moscow, ID, 83844, USA \\ ${ }^{4}$ Assistant Professor, William Jewell College, Liberty, MO 64068, USA \\ ${ }^{5}$ Professor and Director of Graduate Programs, Parks College of Aviation, Engineering and Technology, Saint \\ Louis University, St. Louis, MO 63103, USA \\ Email: ashiquzzamanm@slu.edu, Jdschmeltz@hornershifrn.com, aibrahim@uidaho.edu, \\ lindquistw@william.jewell.edu, rhindi@slu.edu
}

\begin{abstract}
An investigation was performed to assess the performance of the Torsional Analysis of Exterior Girders (TAEG) software in predicting rotation of exterior bridge girders due to eccentric construction loads associated with placement of the concrete deck. TAEG is frequently used by bridge contractors and designers to assess exterior girder rotation and design restraint systems. The primary objective was to investigate whether the program yielded consistent and reliable rotation results as compared to field measurements taken during bridge deck placements. The TAEG software was used to analyze four bridge construction projects and the results were compared to field measurements and results obtained from a finite element analysis (FEA). A secondary objective was to investigate how the program utilizes different bridge and construction parameters. Based on rotations measured in the field and determined using the finite element modeling, the program did not consistently yield accurate results which varied significantly based on the specific bridge configuration and loading conditions. This inconsistency was most likely a result of differences between field conditions and ideal conditions used by the software for analysis.
\end{abstract}

Keywords: Deck overhang, exterior girder rotation, construction load, steel girder, TAEG software

\section{Introduction}

Bridge decks regularly overhang past the exterior girder in order to increase the width of the bridge and also to limit the number of longitudinal girders (Fasl 2008, Ariyasajjakorn 2006). The width of the overhang is typically selected in order to use the same exterior and interior girders. The overhang is supported during construction using formwork supported by overhang brackets which are attached to the top flange of the exterior girder with clips and their inclined leg rests against the lower portion of the girder web. Figure 1 shows the overhang setup and geometry used for analysis. In this case, the overhang bracket holding the exterior formwork also holds the screed rails allowing the screed to reach and finish nearly the entire width of the concrete deck (Roddis et al. 2005). Figure 1 also shows the setup in which the loads are placed along the exterior girder. It is possible to set the screed rails directly over the exterior girders, but the preferred construction method is to set them up on the overhang due to the ability to reach $95 \%$ of the deck without having to move the rails (Suprenant 1994). This is the setup utilized for the bridges in this study.

Construction of the deck overhang using a bracket system (similar to that shown in Figure 1) leads to torsional moments on the exterior girder - a loading which is typically not considered during the design and selection of the exterior girder sections. These moments can lead to excessive rotation of the exterior girder which may result in thin bridge decks, reduced concrete cover, and uncomfortable driving. Rotation of the exterior girder is shown in Figure 2 with rigid body rotation assumed for simplicity and purposes of analysis (Roddis et al. 2005). 
Previous research (Ashiquzzaman et. al. 2016, Ariyasajjakorn 2006, Trejo et. al. 2008) focused on the effects of overhang brackets and loading during construction for the purpose of evaluating rotation restraint systems. Separate research exists for both steel and prestressed girder bridges. A comprehensive study was performed by the University of Texas at Austin to analyze various bridge parameters which affect the lateral deflection of steel bridge girders due to overhang loading (Yang et. al., 2010). Many parameters were investigated, including overhang width, girder span, web stiffener spacing, height of the overhang bracket, width of the top flange, and web imperfections. Findings of the study include: (i) girder web deformations increase as the slenderness of the web increases, (ii) deformation of girder web increases as the overhang bracket leg is moved closer to the top flange of the girder, (iii) transverse web stiffeners help to restrict web deformations, (iv) increasing the overhang width increases the resulting lateral deflection of the web, and (v) P- $\Delta$ effects and initial imperfections in the girder web have negligible effects on lateral deflection (Yang et al. 2010).

Clifton and Bayrak (2008) investigated prestressed concrete girders and their behavior when overhang brackets are used during construction. This analysis was performed experimentally with multiple girder shapes and several types of commercial overhang brackets. Studies were performed using a 20.3-cm thick deck and a 91.4-cm overhang. The following conclusions were drawn: (i) cracking occurred in the top flange, (ii) reinforcement in the top flange of prestressed concrete girders should consist of No. 10 bars spaced at a maximum of $15.2-\mathrm{cm}$, and (iii) the cracking load was reduced substantially once the steel hanger was placed within 30.4-cm of the edge of top flange (Clifton and Bayrak, 2008).

The widely used Torsional Analysis of Exterior Girders (TAEG) software utilizes the "flexure analogy" which assumes that torsional loads on a bridge girder are primarily carried by flanges in minoraxis bending (Roddis et. al. 1999). This analogy analyzes the top and bottom flanges independently since the boundary conditions vary significantly between the two. The program uses a three-span fixedend continuous beam analysis model for determining torsional stresses which are calculated using the stiffness method. Previous work by Roddis et al. (1999), however, did not compare rotation values which were calculated using TAEG with field-measured rotations.

The objective of this study is to evaluate the TAEG program and to assess efficacy as an analysis tool for the expected rotation of the exterior girder due to eccentric construction loading. This study can be used to draw conclusions about the ability of the program to estimate girder rotation and the suitability of the program for use by construction engineers and contractors.

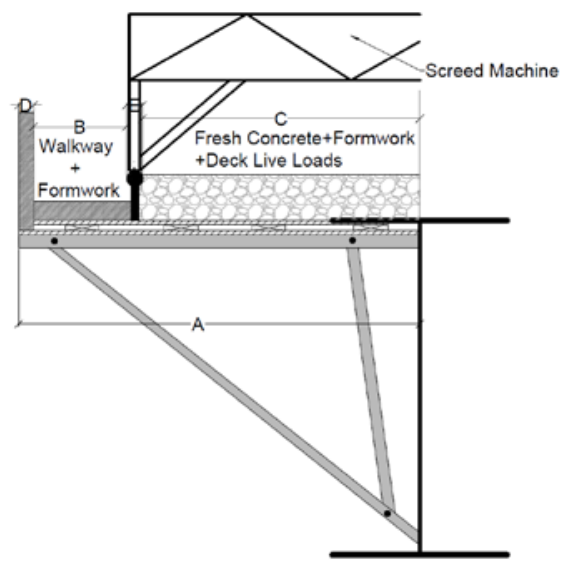

Figure 1. Overhang bracket setup with bracket and load placement 


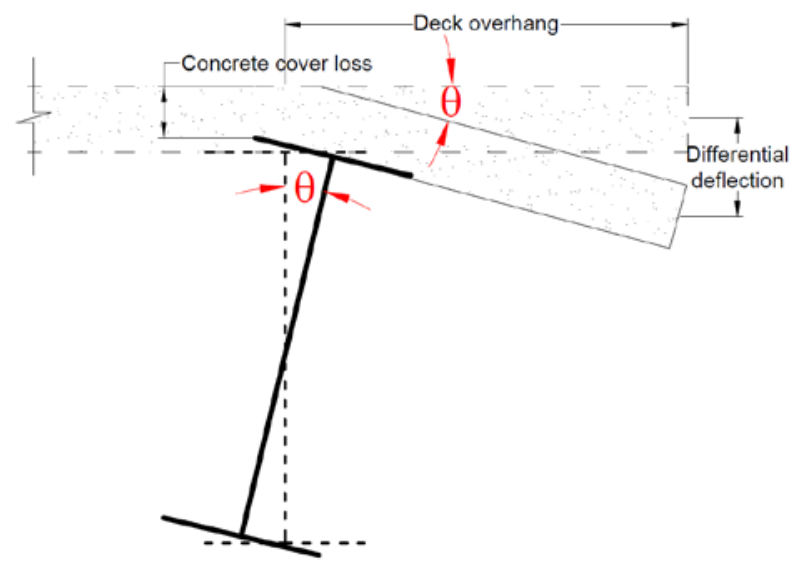

Figure 2. Rigid body rotation of exterior girder and subsequent rotation of the deck overhang

\section{Description of TAEG Program}

The Torsional Analysis of Exterior Girders program was developed by the University of Kansas and the Kansas Department of Transportation (KDOT) to analyze the response of exterior steel bridge girders due to loading associated with construction of concrete bridge decks. The program requires the following to perform the analysis:

i. Properties of the exterior girder, including the dimensions of the flanges and web and the grade of the steel,

ii. Bridge geometry including girder spacing, number of girders, spacing between permanent lateral supports, span lengths, and information relating to the continuity of transverse tie bars (designated TT) and timber blocks (designated TB) over the width of the bridge,

iii. Information on the permanent lateral supports, including the dimensions and geometry of the diaphragms or cross frames,

iv. Information on the temporary lateral supports including transverse tie bars (TT) and timber blocks (TB). The program requires the number of temporary lateral supports between permanent lateral supports, how they are spaced, and their cross-sectional area, and

$v$. The geometry of the overhang brackets, the loads of the screed and finishing machine, weight of plastic concrete, and connection details of the permanent lateral supports.

\section{$3 \quad$ Analysis Assumptions}

In addition to several limitations and assumptions utilized by the TAEG program (Roddis et. al. 2005), some supporting design assumptions were used by the researchers to perform the analysis, as described next. The TAEG program assumes that the plastic concrete weight is only applied to the tributary area of the exterior girder. These loads are in fact placed on both the exterior and interior girders, although the program makes this assumption to obtain a more conservative estimate of the exterior girder response. The program also assumes that the entire span of the bridge is placed at once so that the exterior bay is entirely loaded by plastic concrete in addition to the weight of the finishing machine. The distribution of these loads is shown in Figure 3.

The program assumes that the maximum rotation occurs at mid-span of the longest span of the bridge, as this constitutes the location farthest from the piers where rotation is assumed to be negligible. Therefore, the program only reports the mid-span rotation of the exterior girder in the longest span.

The TAEG program requires uniform spacing of the permanent lateral supports for each span. When spacing for the permanent lateral supports was not uniform throughout the bridge span (as is frequently the case), the spacing value at mid-span was input into the program as the spacing between permanent lateral supports as recommended by KDOT. 
The width of the temporary walkway along the exterior girder was assumed to be 60.9 -cm for all bridges analyzed based on observations in the field. The live loads for the walkway and slab were assumed to be $718.2-\mathrm{N} / \mathrm{m}^{2}$ as recommended by the Indiana Department of Transportation Design Manual (INDOT 2013). All overhang brackets were assumed to be placed such that the bottom of the bracket was 15.2 -cm from the bottom flange of the exterior girder based on observations in the field.

The temporary lateral supports and setup used for the bridges in this study are shown in Figure 4 specifically No. 13 transverse tie bars (TT) and 10-cm $\times 10-\mathrm{cm}$ timber blocks (TB) assumed to be spaced at $122-\mathrm{cm}$. The TAEG program limits the number of temporary lateral supports (tie bars and timber blocks) between permanent supports (diaphragms or cross frames) to three or less. The program assumes perfect connections between the temporary lateral supports and the bridge girders, however, there were some inconsistencies noted in the field including loose ties and improperly shimmed blocks. These inconsistencies affect the stiffness of the girder and influence the rotational response prior to becoming fully engaged.

The TAEG program is applicable for multi-girder, medium span, simple or continuous, composite or non-composite, steel rolled beam or plate girder bridges. The software uses a 3-span analytic model with fixed ends and pinned intermediate supports.

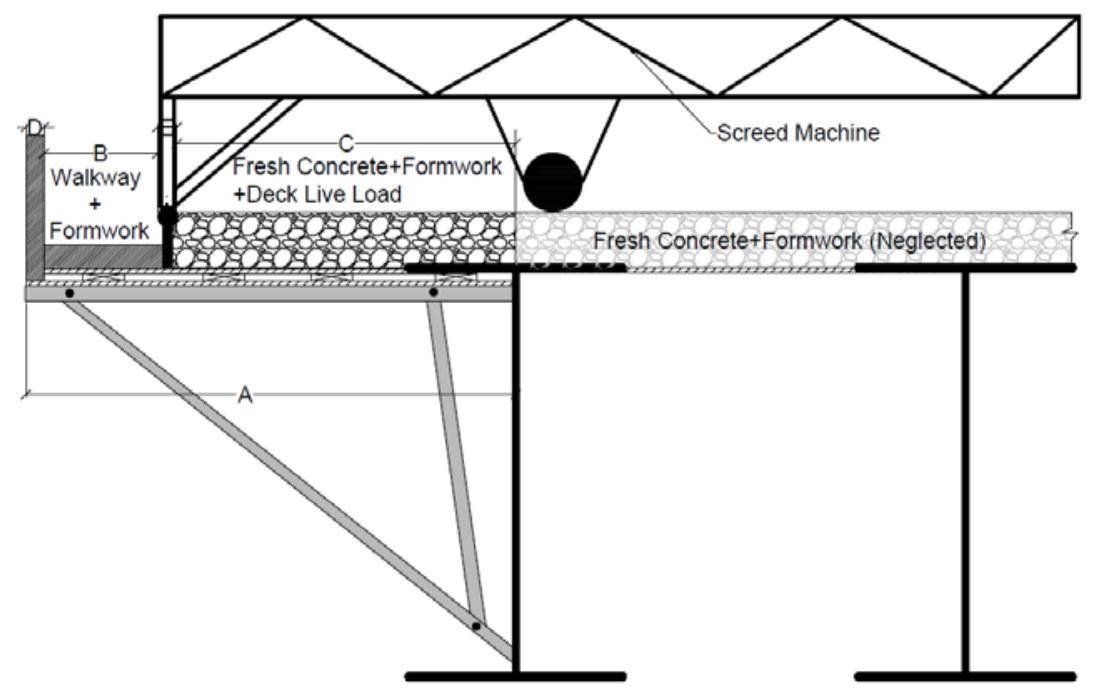

Figure 3. Placement of loads in the TAEG program

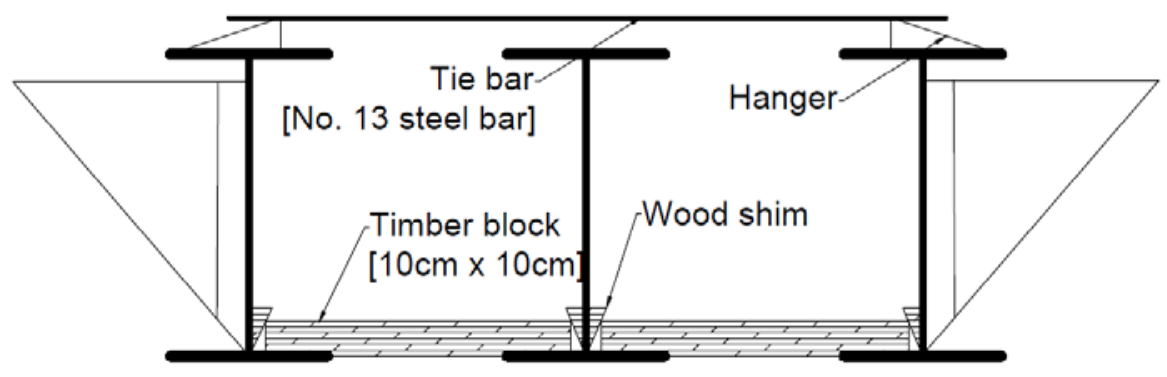

Figure 4. Tie bar and timber block setup 


\section{Application of the TAEG Program}

\subsection{Terminology}

Field Values: The exterior girder rotations measured in the field at mid-span of the four bridges included in the study are referred to as field values.

Full or Equivalent Cross Sectional Area: The TAEG program limits the number of temporary lateral supports (tie bars and timber blocks) located between permanent lateral supports (diaphragms or cross frames) to three or less. If the number of temporary lateral supports exceeds three, then an equivalent cross-sectional area is utilized and larger (with equivalent cross section) supports are placed within the span to produce an approximately equivalent lateral torsional stiffness. If the number of temporary lateral supports exceeds three and is an odd number, then three temporary lateral supports are input with an equivalent cross-sectional area to satisfy the spacing requirement. If the number of temporary lateral supports exceeds three and is an even number, then two temporary lateral supports are input in order to preserve the arrangement of the temporary lateral supports. Temporary lateral supports are evenly distributed between permanent lateral supports. The definition of the full or equivalent cross sectional areas is shown in Figure 5 and the different configurations of temporary lateral supports are described below:

3 Transverse Ties (TT) and 3 Timber Blocks (TB): Placement of three tie bars and timber blocks spaced at equal intervals between permanent lateral supports.

2 Transverse Ties (TT) and 2 Timber Blocks (TB): Two ties and blocks spaced at equal intervals between permanent lateral supports.

No Timber Blocks (TB) and Full Transverse Ties (TT): Exclusion of the timber blocks and the full or equivalent cross-sectional area arrangement is used for tie bars.

No Transverse Ties (TT) and Full Timber Blocks (TB): Exclusion of the tie bars and the full or equivalent cross-sectional area arrangement is used for timber blocks.

1 Timber Block (TB) and 1 Transverse Tie (TT) (center): Inclusion of only one tie bar and one timber block centered between permanent lateral supports.

No Timber Blocks (TB) or Transverse Ties (TT): Tie bars and timber blocks are excluded from the analysis.

Standard size tie bar or timber blocks: The full cross-sectional area for the temporary lateral supports, meaning $10-\mathrm{cm} \times 10-\mathrm{cm}$ for the timber blocks and No. 13 tie bars.

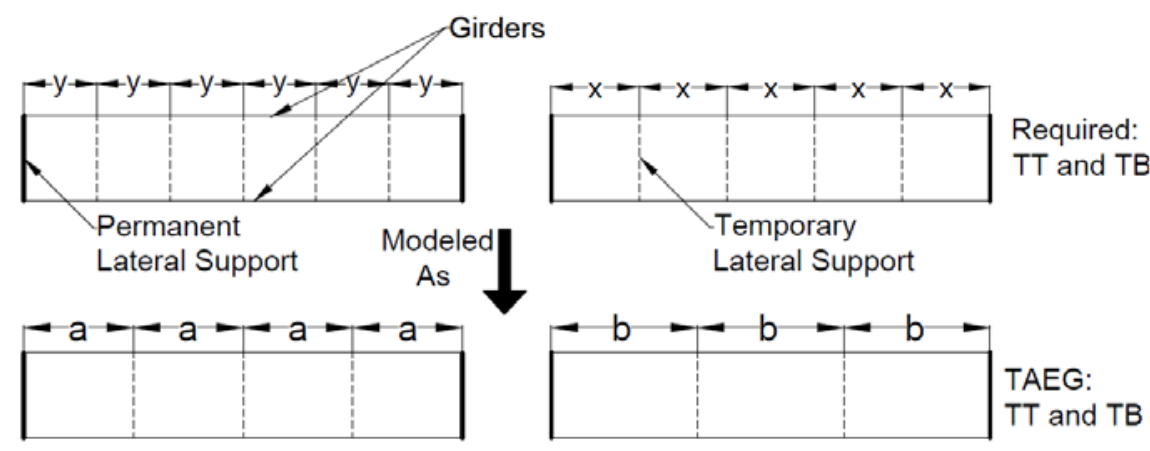

Figure 5. Definition of Full or Equivalent Cross Sectional Areas

\subsection{Description of the Bridges}

Four bridges were inspected during construction and analyzed using the TAEG program. One of these bridges was investigated twice due to a difference in the spacing of the diaphragms on the two exterior panels of the bridge. All bridges were continuous steel girder bridges. The decks for these bridges were finished using a screed machine which was setup along the outside edge of the overhang, as shown in 
Figure 3. A description of these bridges with the information necessary for analysis using the TAEG program is shown in Table 1.

The arrangement of the tie bars and timber blocks was varied for each of the bridges to help account for uncertainty with their placement in the field and program limitations. Arrangements evaluated for each bridge include: (i) full or equivalent cross sectional area for both the tie bars and timber blocks spaced at even intervals between permanent lateral supports, (ii) placement of two or three tie bars and timber blocks spaced at even intervals between permanent lateral supports, (iii) exclusion of the tie bars or exclusion of the timber blocks, (iv) inclusion of only one tie bar and one timber block centered between permanent lateral supports, and (v) tie bars and timber blocks neglected altogether.

Table 1. Description of the bridges

\begin{tabular}{|c|c|c|c|c|c|c|}
\hline & & \multirow[t]{2}{*}{ Bridge A } & \multirow[t]{2}{*}{ Bridge B } & \multirow[t]{2}{*}{ Bridge $\mathrm{C}$} & \multicolumn{2}{|c|}{ Bridge D } \\
\hline & & & & & D_S1 & D_L2 \\
\hline \multicolumn{2}{|l|}{ Girder size } & $\begin{array}{l}\text { W762×147- } \\
\text { mm }\end{array}$ & $\begin{array}{l}1981.2 \mathrm{~mm} \\
\text { Plate girder }\end{array}$ & $\begin{array}{c}\text { W762 } \\
\times 196.8-\mathrm{mm}\end{array}$ & $\begin{array}{l}1219.2 \mathrm{~mm} \\
\text { Plate girder }\end{array}$ & $\begin{array}{l}1219.2 \mathrm{~mm} \\
\text { Plate girder }\end{array}$ \\
\hline \multicolumn{2}{|c|}{ Girder pacing } & $1930 \mathrm{~mm}$ & $1980 \mathrm{~mm}$ & $2200 \mathrm{~mm}$ & $2240 \mathrm{~mm}$ & $2240 \mathrm{~mm}$ \\
\hline \multicolumn{2}{|c|}{ No. of girders } & 7 & 6 & 3 & 7 & 7 \\
\hline \multicolumn{2}{|c|}{ No. of span } & 3 & 4 & 3 & 2 & 2 \\
\hline \multicolumn{2}{|c|}{ Overhang width } & $965.2 \mathrm{~mm}$ & $1016 \mathrm{~mm}$ & $1054.1 \mathrm{~mm}$ & $901.7 \mathrm{~mm}$ & $901.7 \mathrm{~mm}$ \\
\hline \multicolumn{2}{|c|}{$\begin{array}{l}\text { Type of permanent lateral } \\
\text { support }\end{array}$} & Diaphragm & Cross frames & Diaphragm & Diaphragm & Diaphragm \\
\hline \multicolumn{2}{|c|}{$\begin{array}{l}\text { Spacing between permanent } \\
\text { lateral support at mid-span }\end{array}$} & $5250 \mathrm{~mm}$ & $7180 \mathrm{~mm}$ & $6860 \mathrm{~mm}$ & $3310 \mathrm{~mm}$ & $6610 \mathrm{~mm}$ \\
\hline \multicolumn{2}{|c|}{$\begin{array}{l}\text { Diaphragm to girder } \\
\text { connection }\end{array}$} & $\begin{array}{c}\text { Bolted } \\
\text { connection }\end{array}$ & $\begin{array}{c}\text { Welded } \\
\text { connection }\end{array}$ & $\begin{array}{c}\text { Welded } \\
\text { connection }\end{array}$ & $\begin{array}{c}\text { Welded } \\
\text { connection }\end{array}$ & $\begin{array}{c}\text { Welded } \\
\text { connection }\end{array}$ \\
\hline \multicolumn{2}{|c|}{ Skewness } & $24^{\mathrm{o}}$ & Non-skewed & Non-skewed & Non-skewed & Non-skewed \\
\hline \multicolumn{2}{|c|}{ Deck thickness } & $203.2 \mathrm{~mm}$ & $203.2 \mathrm{~mm}$ & $209.6 \mathrm{~mm}$ & $203.2 \mathrm{~mm}$ & $203.2 \mathrm{~mm}$ \\
\hline \multirow{4}{*}{ Span length } & $1^{\text {st }} \operatorname{span}$ & $12090 \mathrm{~mm}$ & $53340 \mathrm{~mm}$ & $13930 \mathrm{~mm}$ & $36510 \mathrm{~mm}$ & $36510 \mathrm{~mm}$ \\
\hline & $2^{\text {nd }} \operatorname{span}$ & $15770 \mathrm{~mm}$ & $60960 \mathrm{~mm}$ & $16310 \mathrm{~mm}$ & $36510 \mathrm{~mm}$ & $36510 \mathrm{~mm}$ \\
\hline & $3^{\text {rd }} \operatorname{span}$ & $12700 \mathrm{~mm}$ & $60960 \mathrm{~mm}$ & $13930 \mathrm{~mm}$ & & \\
\hline & $4^{\text {th }} \operatorname{span}$ & & $53340 \mathrm{~mm}$ & & & \\
\hline
\end{tabular}

All the bridges were instrumented in the $2^{\text {nd }}$ span

${ }^{1}$ Bridge D_S: Bridge D with shorter diaphragm spacing in one exterior panel.

${ }^{2}$ Bridge D_L: Bridge D with larger diaphragm spacing in other exterior panel.

Bridge A: Three-span skewed bridge (W-section girder): Bridge A has three spans with seven longitudinal girders and a 203.2-mm deck. The longitudinal girders are spaced at 1930-mm with span lengths of 12090-mm, 15770-mm, and 12700-mm. Diaphragm spacing is inconsistent and varies within each span, including the span analyzed. Diaphragms are used as permanent lateral supports and consist of $12 \mathrm{WF} 40$ beams bolted at the center of the girder web. The bridge has a $24^{\circ}$ skew resulting in asymmetric loading as the screed was setup perpendicular to the direction of traffic. The actual bridge has four transverse tie bars and timber blocks between diaphragms, so two tie bars and timber block arrangement were used for the equivalent cross sectional area case as an input for TEAG.

Bridge B: Four-span non-skewed bridge (plate girder): Bridge B has four spans with six longitudinal 1981.2-mm plate girders and a 203.2-mm deck. The longitudinal girders are spaced at 1980mm with span lengths of 53340-mm, 60960-mm, 60960-mm, and 53340-mm. Cross frames are used as permanent lateral supports with $\mathrm{C} 12 \times 25$ top chord members, L $4 \times 4 \times 1 / 2$ bottom chords, and web cross members consisting of $\mathrm{L} 4 \times 4 \times 3 / 8$ angle sections. The actual bridge has five tie bars and timber blocks in-between cross frames (the permanent lateral support), so three tie bars and timber block arrangement were used for the equivalent cross sectional area case as input for TEAG.

Bridge C: Three-span non-skewed bridge (W-section girder): Bridge $\mathrm{C}$ has three spans with three longitudinal girders and a 209.6-mm deck. The deck placement was done in two stages with the monitored deck placement occurring first when approximately half of the deck was placed. Longitudinal 
girders are spaced at 2200-mm. The bridge consists of three spans - one with a length of 13930-mm and the others with a length of 16310-mm. Diaphragms were used as permanent lateral supports and the spacing was consistent within the two end spans but not within the center span, which was the one analyzed as the concrete deck was being placed. Diaphragms consist of W $14 \times 30$ steel sections bolted at the center of the exterior girder web. The actual bridge has five tie bars and timber blocks in-between diaphragms, so three tie bars and timber block arrangement were used for the equivalent cross sectional area case as input for TEAG.

Bridge D: Two-span non-skewed plate-girder bridge: Bridge D has two spans with seven longitudinal girders 1219.2-mm plate girder) and a $203.2 \mathrm{~mm}$ thick deck. Longitudinal girders are spaced at 2240-mm. Both spans are 36510-mm long. Diaphragms are utilized as permanent lateral supports and their spacing varies across the bridge. One of the exterior panels has diaphragms spaced at a close distance (3310-mm). The diaphragms for other exterior girder of the bridge are spaced at twice the distance $(6610-\mathrm{mm})$ as compared to the exterior panel with closely spaced diaphragms. The diaphragms are $\mathrm{C} 15 \times 40$ sections bolted to the center of the girder web. The bridge was analyzed in two scenarios, one case with the closer spacing and the other case with the longer spacing. For the shorter spacing (Bridge D_S), two tie bars and timber block arrangement were used, which was the same as used in the field. For the longer spacing (Bridge D_L), the actual bridge had five tie bars and timber blocks, so three tie bars and timber block arrangement were used as input for TAEG. Field data was only gathered on the side with short diaphragm spacing, as the tilt sensors on the side with longer spacing malfunctioned during deck placement.

\section{$5 \quad$ Locations of the Tilt Sensors}

Tilt sensors were placed in multiple locations along the bridge span including at mid-span. Tilt sensors were located on the bottom flange of the exterior girder and collected rotation measurements throughout the placement of the concrete deck for all bridges. In this study, the maximum rotations measured at mid-span during deck placement were compared to the results obtained from TAEG. Maximum rotations occurred when the placement operations (fresh concrete, finishing screed, construction personnel, etc.) were located at the location of the tilt sensor. The TAEG program includes concrete placed over the entire length of the deck.

\section{Comparison between TAEG Results and Field Data}

For bridge A which has four transverse tie bars and timber blocks between diaphragms, the rotation calculated by TAEG (shown in Figure 6) using the equivalent cross sectional area method underestimated the field-measured rotation by $55.3 \%\left(0.24^{\circ}\right.$ compared to $\left.0.53^{\circ}\right)$, even though TAEG does not place a load on the first interior bay of the bridge. The results using two standard size tie bars and timber blocks, in addition to one standard size tie bar and one timber block placed at the center between diaphragms, were improved, underestimating rotation by $29.9 \%$ and $11.2 \%$, respectively. The results for the other conditions (No TB and Full TT: $1.65^{\circ}$, No TT and Full TB: $1.54^{\circ}$, No TB or TB: $2.99^{\circ}$ ) demonstrated greater error, all well over $180 \%$, as shown in Figure 6 . The accuracy of the results was likely due to poor installation of the temporary lateral supports in the field, as demonstrated by the program gaining accuracy as the support from the temporary lateral supports was reduced.

For bridge B which has five tie bars and timber blocks between cross frames, the results (as shown in Figure 6) for the equivalent cross sectional area arrangement demonstrated little error, overestimating the field rotation by only $5.3 \%\left(0.097^{\circ}\right.$ compared to $\left.0.092^{\circ}\right)$. The results when using three standard sized tie bars and timber blocks also differed only slightly from the field value, overestimating rotation by $15.1 \%$ when compared with field measurements. This can be attributed to the greater depth of the girders used in bridge $\mathrm{B}$ which made the tie bars and timber blocks less necessary to resist torsional moments therefore resulting in less force compared to bridges with shallower girders. Rotations obtained using $2 \mathrm{TT}$ and $2 \mathrm{~TB}\left(0.117^{\circ}\right)$, No TB and Full TT $\left(0.121^{\circ}\right)$, and $1 \mathrm{~TB}$ and $1 \mathrm{TT}\left(0.127^{\circ}\right)$ were similar to the field-measured values. Rotations calculated for arrangements without any tie bars (No TT and Full TB: $0.182^{\circ}$ and $\mathrm{No} \mathrm{TB}$ or $\mathrm{TT}$ : $0.206^{\circ}$ ) illustrate the importance of providing a system to prevent rotation. 
For bridge $\mathrm{C}$ which has five tie bars and timber blocks between diaphragms, the results (as described in Figure 6) for the equivalent cross sectional area arrangement demonstrated significant error, underestimating the field value by $75.8 \%\left(0.17^{\circ}\right.$ compared to $\left.0.46^{\circ}\right)$. None of the cases in bridge $\mathrm{C}$ yielded accurate results, with the closest calculated rotation $\left(0.28^{\circ}\right.$ for the one standard size tie bar and timber block arrangement) 39.1\% lower than the field rotation. The results for the no TB and Full TT $\left(1.18^{\circ}\right)$, no TT and Full TB $\left(1.10^{\circ}\right)$, and no TB or TB $\left(2.16^{\circ}\right)$ did not result in a better correlation, as shown in Figure 6. The difference between the TAEG results and the measured field rotations was most likely due to the unusual arrangement of the diaphragms which could not be modelled properly using TAEG.

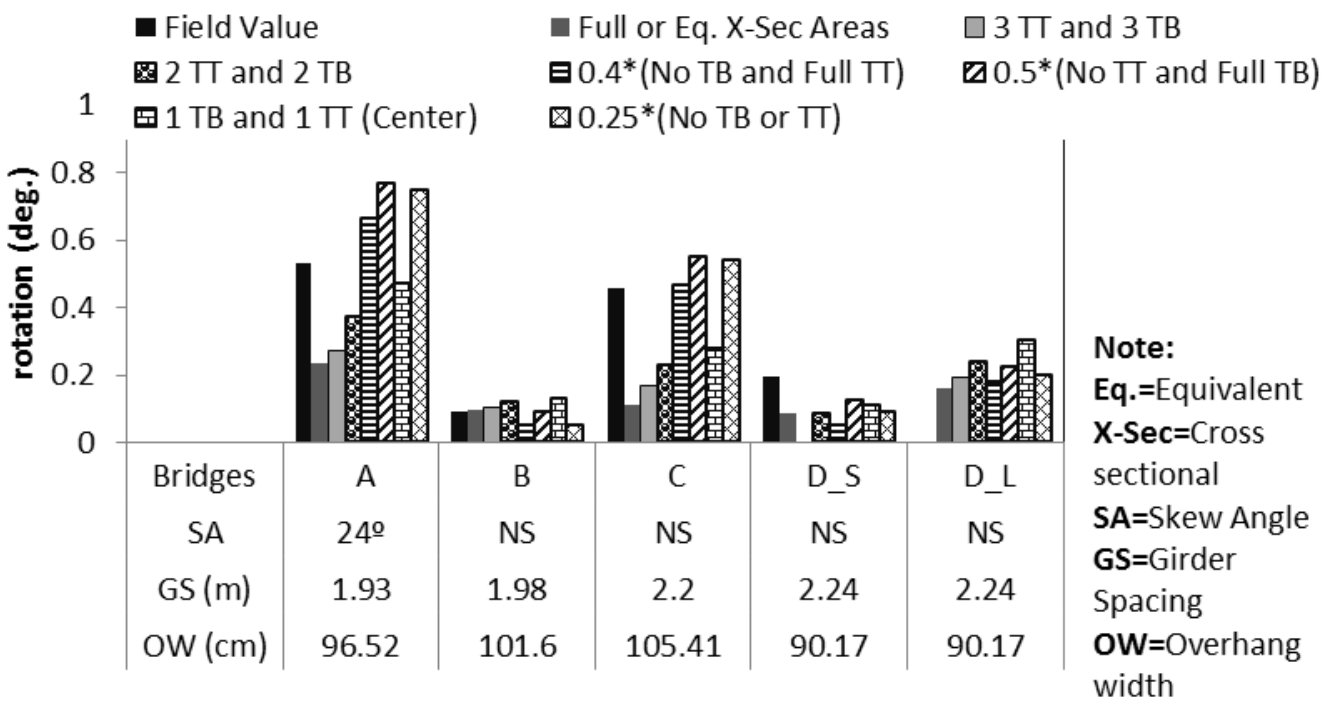

Note: 0.4, 0.5, 0.25 (reducing factors) are respectively used to accommodate the large values of No TB and Full TT, No TT and Full TB, and No TB or TT.

Figure 6. Exterior girder rotation in different tie bar and timber block configurations

For bridge D, both exterior girders were studied in TAEG program as two separate bridges as shown in Table 1 (bridge D_L: exterior panel with widely spaced diaphragms, and bridge D_S: exterior panel with closely spaced diaphragms). In the case of bridge $\mathrm{D}$ _ $\mathrm{S}$ with two tie bars and timber block arrangement modeled directly, TAEG consistently underestimated the rotation measured in the field $\left(0.19^{\circ}\right)$. The other configurations, for instance, full or equivalent cross sectional areas $\left(0.085^{\circ}\right)$, no timber block and full transverse tie bars $\left(0.12^{\circ}\right)$, one timber block and one tie bar $\left(0.11^{\circ}\right)$ show comparatively smaller rotations than field results. The diaphragms were placed at a shorter spacing, so an equivalent cross sectional area case was not necessary as two tie bars and timber blocks satisfied the TAEG spacing requirements. This case underestimated rotation by $50.8 \%$ compared to the field value. The closest value for the shorter spacing scenario was achieved when timber blocks were excluded from the model, underestimating rotation by $29.4 \%$. The TAEG results for no TT and Full TB $\left(0.251^{\circ}\right)$ and no TT or TB $\left(0.368^{\circ}\right)$ showed higher rotations due to the absence of tie bars as compared with the field value. Unfortunately, there was no exterior girder rotation collected from the field for the exterior panel with a large diaphragm spacing (bridge D_L). The rotations for different arrangements of temporary lateral supports for bridge D_L were analyzed in TAEG, and the cases of No TB and Full TT $\left(0.452^{\circ}\right)$, No TT and Full TB $\left(0.447^{\circ}\right)$, and No TB or TT $\left(0.794^{\circ}\right)$ showed large values once compared with the exterior panel with comparatively closely spaced diaphragms (bridge D_S). The full results of the TAEG program and the field values that were utilized for the comparisons are shown in Figure 6 for both the shorter and longer spacing of permanent lateral supports. The accuracy of the results was likely due to poor installation of the temporary lateral supports. 


\section{Comparison of TAEG Results with Finite Element Analysis}

This section presents a comparison between the rotations obtained in the field and a detailed finite element analysis for purposes of calibrating the finite element models. To get deeper insight of the TAEG results, the TAEG rotation results are compared with the finite element analysis.

\subsection{Finite Element Modeling}

All the bridges were modeled using the finite element code Abaqus/Standard 6.13 and the results were compared to the results obtained in the field and from the TAEG program. The girders and diaphragms were modeled using shell elements (S4R), tie bars and timber blocks were modeled using truss elements (T3D2), and the overhang brackets were modeled using beam elements (B31). Additional details regarding the finite element analysis are provided by Ashiquzzaman et al. (2016).

Weight of the fresh concrete was calculated based on the tributary area of the girders and then distributed over the top surface of the girder flange. Concrete placed on the overhang was calculated separately and distributed evenly among the steel brackets. The fresh concrete load was distributed from the abutment of the bridge to the middle of the longest span. The screed load was divided equally into two point loads and placed at mid-span at a distance (distance "C" in Figure 1) from the center line of the exterior girder to the tip of the deck overhangs. The boundary conditions were modeled to simulate the bridges as continuous.

Surface to surface tie connections were used to connect the diaphragms/cross frames to the girders, and nonlinear "translator" link elements were utilized to connect the tie bars and timber blocks to the girders. Node-surface tie connections were used to connect the steel brackets to the exterior girders' web and flange.

The elastic modulus of steel and timber were taken as $200 \mathrm{GPa}$ and $8.96 \mathrm{GPa}$, respectively, with Poison's ratio for steel and timber equal to 0.30 and 0.37 , respectively. Figure 7 shows the sample finite element model built for bridge B.

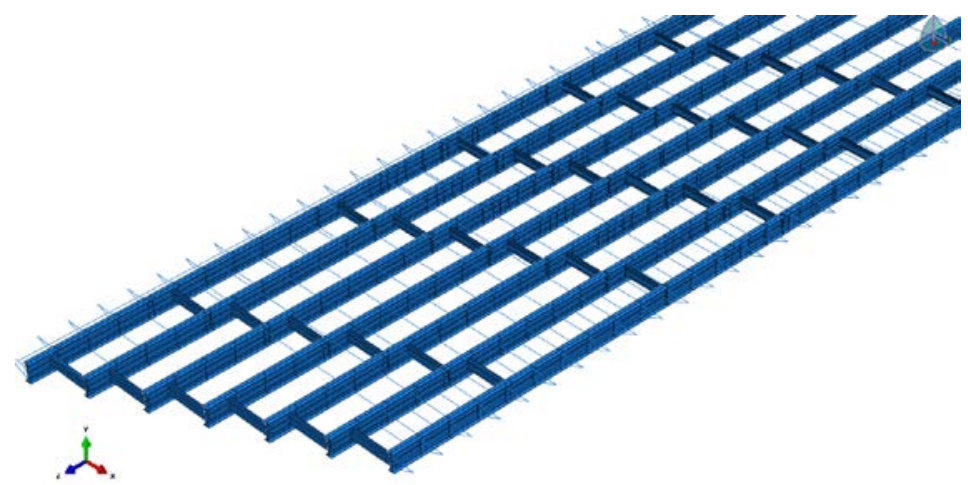

Figure 7. Sample Abaqus model of Bridge C

\subsection{Finite Element Modeling}

The exterior girder rotation obtained from the bridge finite element models showed good agreement with the measured field data for all the bridges, as shown in Figure 8. For bridge A, the rotation calculated from the finite element analysis is $7.54 \%$ smaller than the field-measured rotation $\left(0.49^{\circ}\right.$ compared to $0.53^{\circ}$ ). For bridge B (as shown in Figure 8), the exterior girder rotation obtained from the finite element analysis $\left(0.063^{\circ}\right)$ and the field $\left(0.092^{\circ}\right)$ showed excellent agreement. For bridge C, the rotation calculated from the finite element analysis $\left(0.40^{\circ}\right)$ is $13.04 \%$ smaller than the rotation measured in the field $\left(0.46^{\circ}\right)$. For bridge D_S (shown in Figure 8), the rotation obtained from the finite element analysis $\left(0.189^{\circ}\right)$ is very similar to the field-measured rotation $\left(0.196^{\circ}\right)$. In most of the cases, TAEG outputs underestimated the rotation from the field and finite element analysis for the short spacing (bridge D_S) 
of permanent lateral supports. In the case of bridge D_L, the estimated exterior girder rotation $\left(0.47^{\circ}\right)$ showed higher value than the rotation measured in the field $\left(0.196^{\circ}\right)$ for the exterior girder with closely spaced permanent lateral support (bridge D_S). It means that the spacing between permanent lateral supports plays an important role in controlling exterior girder rotation. The results (as shown in Figure 8) for the equivalent cross sectional area $\left(0.16^{\circ}\right)$, three transverse tie bars and timber blocks $\left(0.19^{\circ}\right)$, two transverse tie bars and timber blocks $\left(0.24^{\circ}\right)$, and one transverse tie bar and timber block at the center $\left(0.3^{\circ}\right)$ demonstrated more errors, underestimating the FEA value $\left(0.47^{\circ}\right)$ by an average of $36-67 \%$. The results for the cases of "No TB and Full TT $\left(0.452^{\circ}\right)$ " and "No TT and Full TB $\left(0.447^{\circ}\right)$ " showed closer values once compared with rotation calculated from the FEA. The case without any tie bars and timber block showed $69 \%$ higher rotation than FEA rotation for D_L bridge.

\subsection{Additional Comparison with FEA Results}

Two additional single-span bridge models were developed using the calibrated finite element models to characterize how well the TAEG program predicts the results compared to the finite element model when the only difference is bridge skew.

\subsection{Bridge Description}

Two single-span bridges were modeled in Abaqus/Standard 6.13 including a non-skewed bridge and a skewed $\left(30^{\circ}\right)$ bridge. The same girder $(\mathrm{W} 30 \times 124)$, diaphragm $(\mathrm{C} 12 \times 25)$ sections and span length $[24.38$ $\mathrm{m}]$ were used for both bridges. Longitudinal girders $($ W30×124) were spaced at $2.13 \mathrm{~m}$.

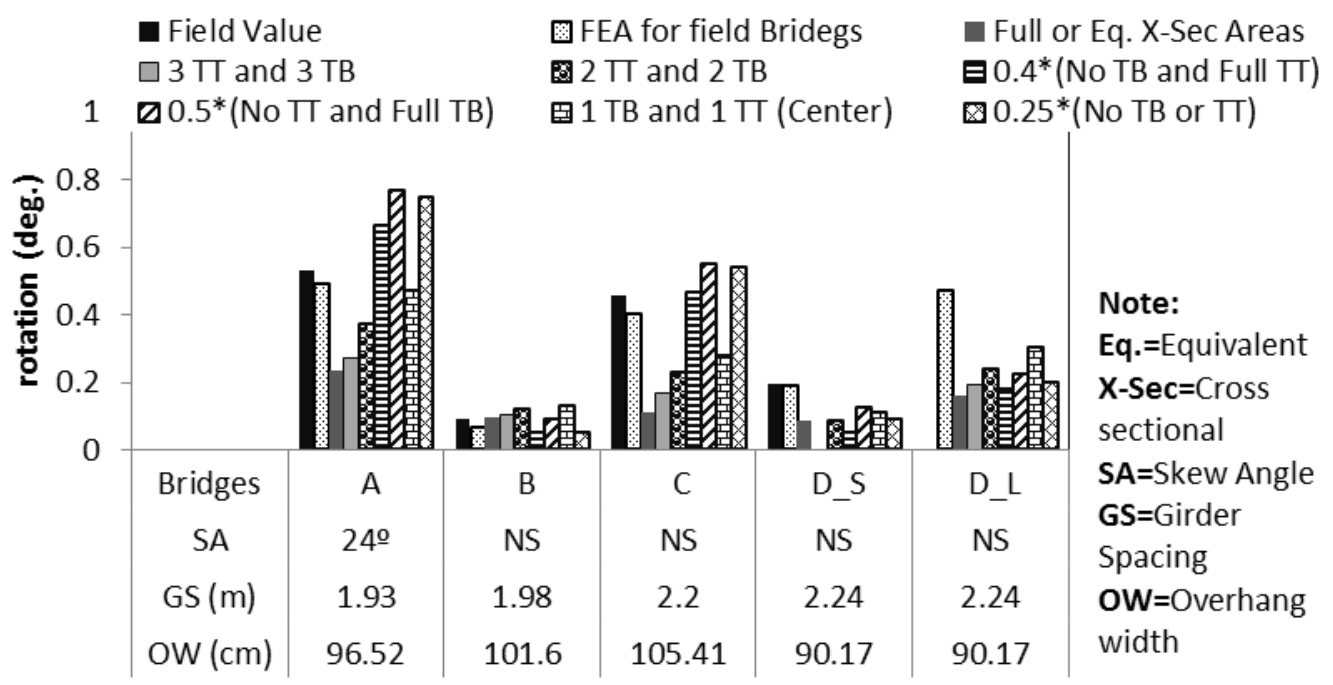

Note: $0.4,0.5,0.25$ (reducing factors) are respectively used to accommodate the large values of No TB and Full TT, No TT and Full TB, and No TB or TT.

Figure 8. Comparison of TAEG rotation with field and FEA rotation

For the non-skewed bridge (the FE model is shown in Figure 9), the permanent lateral supports were spaced evenly at $4.88 \mathrm{~m}$. For this case, the temporary lateral supports could be properly placed using TAEG with three tie bars and timber blocks placed between the permanent diaphragms and spaced at $121.9 \mathrm{~cm}$. For the skewed bridge, the non-skewed bridge configuration was modified to have a skew of $30^{\circ}$. The diaphragms were placed perpendicular to the longitudinal girders. Due to $30^{\circ}$ skew angle, the diaphragms were distributed within a reduced girder length. To make the arrangement of the diaphragms function properly in the Abaqus model, the spacing (evenly spaced) between diaphragms was changed to $4.57 \mathrm{~m}$. Within the TAEG program, the skew was adjusted to its setting of greater than 20 degrees and asymmetric loading. Within this finite element analysis, temporary lateral supports were included and assumed to be attached to the girders, and therefore considered fully engaged. 


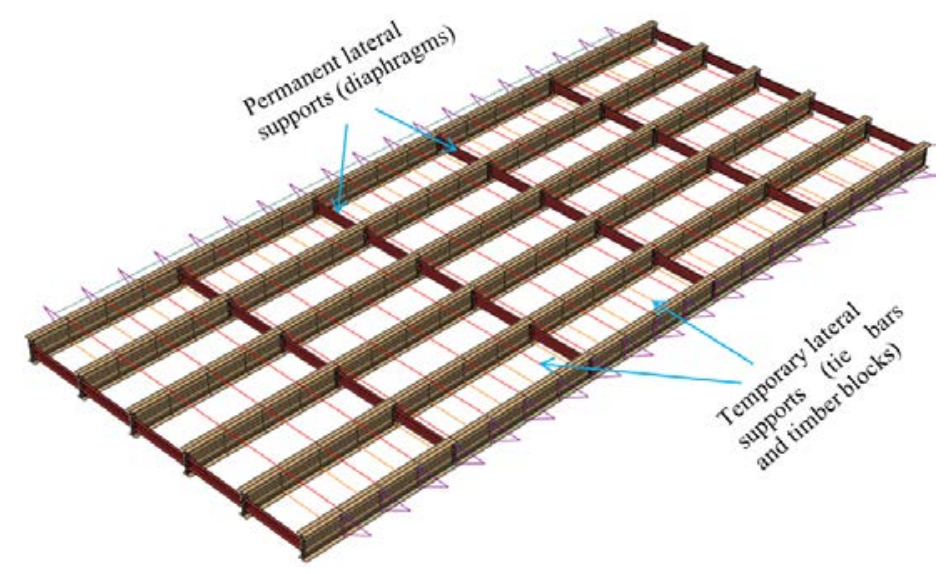

Figure 9. Abaqus model of non-skewed bridge with evenly spaced diaphragms

\subsubsection{Comparison between TAEG and FEA Results}

For the non-skewed bridge, the TAEG program yielded a rotation of $0.40^{\circ}$ at mid-span. The finite element model achieved rotation results of $0.43^{\circ}$ at the bottom flange of the exterior girder and $0.45^{\circ}$ at the web.

For the skewed bridge, the results of the finite element model were in much less agreement. The TAEG program calculated a single rotation of $0.35^{\circ}$ at mid span of both exterior girders. Whereas, the Abaqus model calculated a rotation of $0.17^{\circ}$ on the side closer to the pier and 0.63 degrees on the side which was further from the pier as shown in Figure 10. Based on this comparison, the TAEG program yielded results which were fairly consistent with the results of the finite element program when the bridge did not have skew. The engagement and effectiveness of the temporary lateral supports and the influence of the bridge skew angle appears to be the largest single factor affecting the accuracy of the TAEG program. When the finite element included full engagement for the temporary lateral supports; the results for the finite element program were fairly consistent with the results from TAEG program and when the bridge did not have skew.

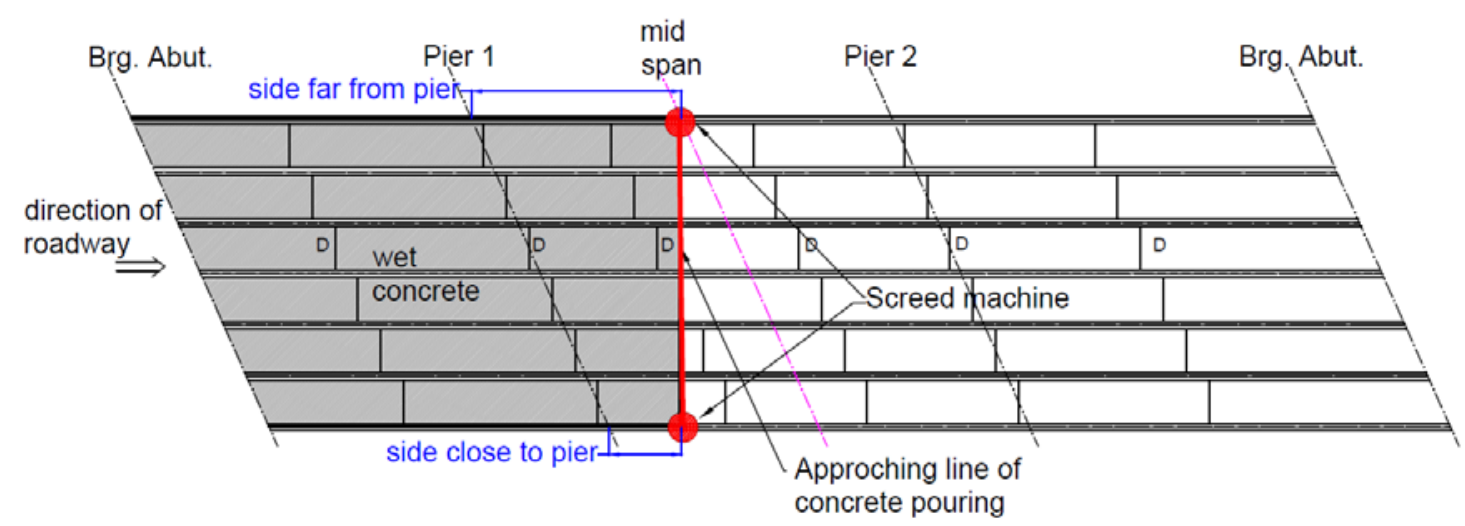

Figure 10. Approaching line of concrete placement during construction

\section{Conclusions and Recommendations}

Based upon the results of this study, the TAEG program seems to contain several limitations which affect its overall accuracy and reliability. These limitations include: 
The software does not simulate actual conditions during deck construction. The software considers the tie bars and timber blocks and their connection to girders as ideal. This assumption is not necessarily consistent with actual field conditions.

The program does not properly consider the effects of skew angle in determining girder rotation.

Based on the field and finite element analysis, the observed exterior girder rotations were in good agreement for all the bridges. But, comparing field and FE results with the calculated exterior girder rotation using TAEG, no solid consistency in the results was found to draw a generalized conclusion.

Different bracing schemes were used to overcome TAEG program limitations and approximate actual conditions in the field. None of the alternate bracing configurations worked consistently across the bridges examined to reduce errors.

The spacing of permanent lateral supports is also significant, as the arrangement of these supports plays a significant role in affecting the global stiffness of the exterior girder. The program is unable to include multiple spacings for the permanent lateral supports.

Acknowledgments: The financial support of the Illinois Department of Transportation that made this research project possible is greatly appreciated.

\section{References}

1. AISC Marketing, Inc., Design for Concrete Deck Overhang Loads. Final Report, AISC Marketing, INC., June 15, 1990.

2. Ariyasajjakorn, D. "Full scale testing of overhang falsework hangers on NCDOT modified bulb tee (MBT) girders". (Master's Thesis). North Carolina State University, North Carolina, U.S.A. 2006.

3. Ashiquzzaman, M., Hui, L., Schmeltz, J., Merino, C., Bozkurt, B., Ibrahim, A., Lindquist, W., and Hindi, R. "Effectiveness of exterior beam rotation prevention systems for bridge deck construction". Rep. No. FHWA-ICT16-015, Illinois Department of Transportation, Springfield, Illinois. 2016

4. Clifton, S. and Bayrak, O. "Bridge Deck Overhang Construction". Rep. No. IAC 88-5DD1A003-2, Texas Department of Transportation, Texas. 2008.

5. Fasl, J. D. "The influence of overhang construction on girder design". (Ph.D. Dissertation). University of Texas at Austin, Texas, U.S.A. 2008.

6. Indiana Department of Transportation (INDOT). Part 4: Structural Design Manual. Indianapolis (IN), USA. 2013.

7. Roddis, K. and Kulseth, P. User's Manual. TAEG 2.1. The University of Kansas and the Kansas Department of Transportation, Topeka, KS, USA. 2005.

8. Roddis, K., Kriesten, M., and Liu, Z. "Torsional Analysis of Exterior Girders". Report No. K-TRAN: KU-96-3, Kansas Department of Transportation, Kansas. 1999.

9. Suprenant, B. "Setting Screed Rails for Bridge Deck Paving. Concrete Construction", the Aberdeen Group. 1994.

10. Yang, S., Helwig, T., Klingner, R., Engelhardt, M., and Fasl, J. "Impact of Overhang Construction on Girder Design". Report No. FHWA/TX-10/0-5706-1, Texas Department of Transportation, Texas. 2010.

11. Trejo, D., Hite, M. C., Mander, J. B., Mander, T., Henley, M., Scott, R., \& Patil, S. "Development of a precast bridge deck overhang system for the Rock Creek Bridge”. (No. FHWA/TX-08/0-6100-2). 2008. 